Military Technical College

Kobry El-Kobbah, Cairo, Egypt

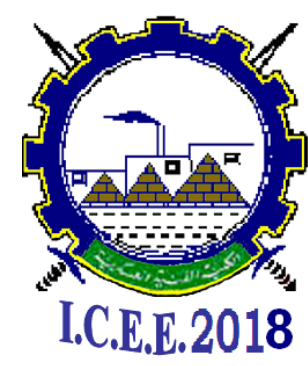

$9^{\text {th }}$ International Conference on

Chemical \& Environmental

Engineering

3-5 April 2018

\title{
DFI-1
}

\section{Crystal Modification, Effective Technique for Enhancement of Solid/Liquid Separation in Chemical Industries; Case Study of Gypsum and phosphoric Acid}

By

\author{
A.K. Ismail ${ }^{1}$, E.A. Abdel Aal ${ }^{1}$ and H. El-Shall ${ }^{2}$
}

\begin{abstract}
:
In view of the national project of cultivation of 1.5 millions Feddans, the need for fertilizers phosphatic and compound - becomes an important element in the economics of the project. The fertilizers are produced from phosphoric acid which in turns is produced from sulphuric acid dissolution of phosphate ores. Two major phosphoric acid projects are under establishment, one in El-Sokhna (Red Sea) and the other in the New Valley (Abu - Tartur) in addition to the already existing plants in "Abu- Zabal " and "Fayoum"

As a result of the reaction between sulphuric acid and phosphate rock, gypsum $\left(\mathrm{CaSO}_{4} \cdot 2 \mathrm{H}_{2} \mathrm{O}\right)$ is formed in the solid phase whereas the liquid phase is phosphoric acid $30 \% \mathrm{P}_{2} \mathrm{O}_{5}$. Solid/liquid separation is the main technological and economic factor in phosphoric acid industry. It is expressed by the filtration rate of gypsum.

Although the reaction between sulphuric acid and phosphate ore is very fast, around 15 minutes; the retention time - time required for gypsum crystal to grow to the shape and size suitable for fast filtration - ranges between $4-8 \mathrm{hrs}$. The percentage of fine gypsum particles should be minimum as it blocks the voids between larger crystals resulting in decreasing the filtration rate. Certain surface active materials (surfactants) are added in special rate to enhance crystal growth. The filtration rate is expressed as tons $\mathrm{P}_{2} \mathrm{O}_{5} / \mathrm{m}^{2} /$ day. It ranges between 3 and 6; the faster the filtration rate the better the economics of the process.

Nile Valley phosphates gave relatively high filtration rates $(3.5-4.5)$ within 6 hrs retention time, whereas as New walley phosphates give filtration rate as low as 3 within 6 hrs retention time. The rate has been doubled after the addition of certain surface active agent. The role of surfactant is to modify the gypsum size (length - width ratio is 3:2) and shape. At the same time it reduces the percent of fine crystals to $<10 \%$.
\end{abstract}

The paper reviews the results achieved from testing of both Nile Valley and New Valley phosphates using continuous units simulating the industrial operation having capacities of 12 $\mathrm{kg} /$ day ore for semi-pilot unit and 3 tons/day using pilot plant unit. The results achieved were up-scaled to the plant level 500/ton/day and the results obtained are comparable as the filtration rate reached 6 compared with 3 without addition of surfactant. 
Military Technical College

Kobry El-Kobbah, Cairo, Egypt

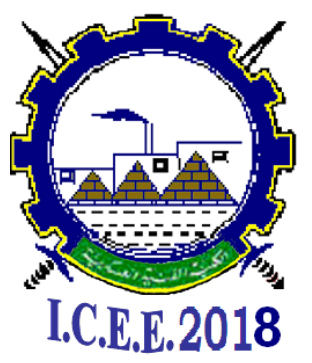

\section{9- International Conference on}

Chemical \& Environmental

Engineering

3-5 April 2018

Trials are continued to utilize a local cost effective reagent to substitute the imported surfactant. Further studied should be carried out to decrease the retention time and thus increasing plant productivity without investment in additional equipment, this will consequently leads to increasing $\mathrm{P}_{2} \mathrm{O}_{5}$ recovery.
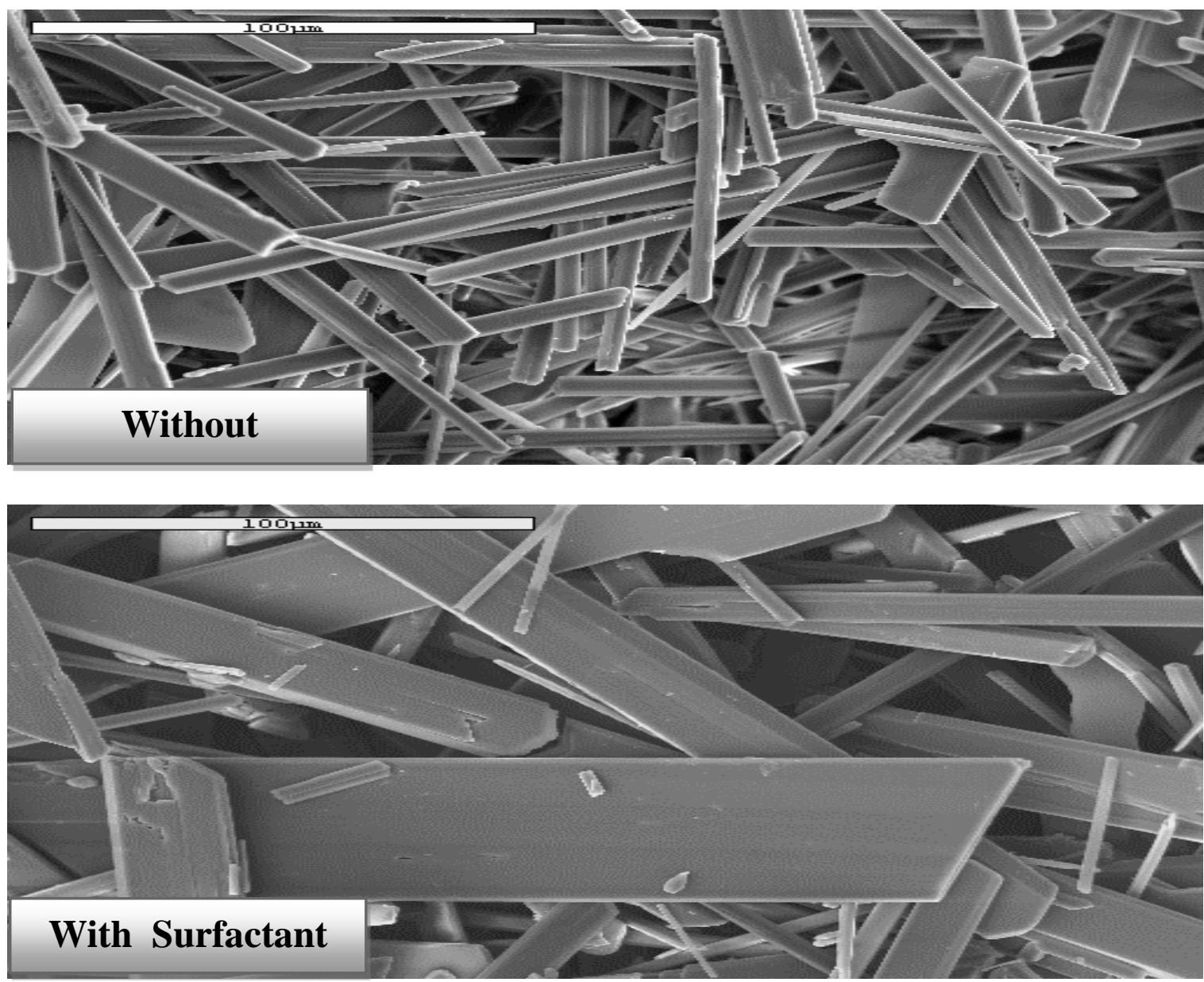

1. Prof A.K.Ismail, corresponding author akismasil_110411@yhoo.com Central Metallurgical Research and Development Institute

2. University of Florida, USA 